\title{
A Dynamic Evolutionary Game Model of Collaborative Innovation in Manufacturing Services Industry and Manufacturing Industry
}

\author{
Deguang Liu \\ Business School of Hohai University, Nanjing 211100, China
}

Received: March 28, 2021. Revised: July 31, 2021. Accepted: August 25, 2021. Published: August 26, 2021.

\begin{abstract}
Collaborative innovation has a significant impact on the efficiency of manufacturing services and manufacturing innovation. In this paper, a collaborative innovation model of manufacturing services and manufacturing is constructed based on the two-dimensional asymmetric evolutionary game basic model. The stable evolution strategy of the model is to be found through the solutions to the replicator dynamic differential equation of both sides of the game. The results show that on the one hand, producer services can rely on the carrier of knowledge capital and human capital to link to the manufacturing process from front to back, and form the forward and backward spillover effect. On the other hand, the knowledge elements in producer services, especially tacit knowledge, are transmitted through the modern network under the common industrial culture atmosphere in the process of continuous industrial interaction and industrial integration, which can promote the sharing and transfer of knowledge, produce interactive innovation, and finally promote the innovation of value chain.
\end{abstract}

Keywords-Manufacturing services industry, Manufacturing industry, Collaborative innovation, Evolutionary game, Structural equation model

\section{INTRODUCTION}

$\mathrm{T}$ he collaborative development of manufacturing services industry and manufacturing industry is a practical problem in economic development[1-2]. As a pillar industry of economic growth, the manufacturing industry has not got rid of the issues of low technological content, low added-value products, the low-end quality, so the innovation of manufacturing industry is imminent[3]. The disparity of innovative resources, poor coordination and other issues in the new situation are particularly prominent, which have become the key obstacles in the implementation of innovation-driven countries[4]. The important way to solve this problem is to break the industrial boundaries of the original manufacturing and producer services industries, and promote innovation efficiency and transformation and upgrading in manufacturing industry through industrial synergy innovation.

As the economy enters the new normal, the boundaries between industries are increasingly blurred under the influence of technology, economy, policy and other environments. No industry can create value independently. If an industry wants to develop better, it must be able to symbiosis with more organizations, more systems and even with the entire external environment [5]. Symbiosis refers to the integration, complementarity and dependence among innovation systems. Symbiotic innovation system is proposed from a more macroscopic perspective based on innovation system. It is the integration of innovation systems of different levels, properties and scales [6]. With the increasing interaction and dependence between producer services and manufacturing industries, symbiotic innovation has become the main trend. The symbiotic innovation is realized by various elements of the system. So how to effectively improve the innovation performance of two industry symbiosis innovation system is an urgent problem to be solved. In other words, it is more likely to be affected by the factors such as institutional input, institutional innovation and industrial performance for a wide range of information resources, and their own innovation ability can better promote the symbiotic performance. At the same time, environmental uncertainty has a certain impact on innovation ability and symbiotic innovation performance.

The interaction relationship between manufacturing services industry and manufacturing industry has been the hot spot of western scholars[7]. With the improvement of economic development, the relationship between manufacturing services and manufacturing has been advanced to a higher level[8], manufacturing upgrading increases the demand for external manufacturing services, both of which can achieve bidirectional embedding[9], resulting in a cumulative causal cycle leading to co-evolutionary co-evolution[10-11]. Nowadays, as the evolution research on the single-level enterprise has reached the limit, co-evolutionary thinking has gradually become the new focus of evolutionary research. More and more scholars have begun to explore the theoretical application system of co-evolution theory, and gradually applied it to different industries and national levels. Industrial collaborative innovation is a process, and the process is nonlinear and dynamically evolved, and it contains multielement, cross-level dynamic process [12]. But the research field mainly concentrates on the level and the dynamic 
mechanism of co-evolution.

In this paper, a collaborative innovation model of manufacturing services and manufacturing is constructed based on two-dimensional asymmetric evolutionary game from the perspective of synergy. The stable evolution strategy of the model is to be found through the solutions to the replicator dynamic differential equation of both sides of the game. The evolutionary stable strategy of the model is found by solving the replicator's dynamic differential equation. In addition, this paper puts forward a dynamic evolutionary game model, and conducts empirical test, aiming to provide valuable guidance for symbiotic innovation.

\section{THE DYNAMIC EVOLUTIONARY GAME MODEL}

In the evolutionary process of collaborative innovation in manufacturing service industry and manufacturing industry, in order to achieve the same interest demands, therefore, the two parties of the game will not just pursue their own maximal interests, on the contrary, they will choose the specific strategies according to the expectation of income in the game process [8]. They will continue to learn and always replace the strategies, the low-income strategy will not replace the highincome strategy in the course of the game. Therefore, the multi-round game will be played until the game system is finally stabilized. In this paper, a two-dimensional asymmetric game model is chosen as the basic model for modeling and analysis.

\section{A. Basic Assumptions}

$H_{1}$ : Both sides of the game are the manufacturing services industry and manufacturing industry respectively. In the collaborative innovation process, the two sides need to play multiple games based on bounded rationality.

$\mathrm{H}_{2}$ : When neither sides choose the collaborative innovation strategy, the normal income can be obtained. Wherein, $x_{1}$ is the net income obtained by Enterprises $i$ in the manufacturing industry which did not take the collaborative innovation strategy and $x_{2}$ is the net income obtained by Enterprises $j$ in the manufacturing services industry which did not take the collaborative innovation strategy.

$H_{3}$ : When both sides choose the cooperative innovation strategy, they can get the benefit of collaborative innovation. Wherein, $x_{3}$ is the net income obtained by Enterprises $i$ in the manufacturing industry which took the collaborative innovation strategy and $x_{4}$ is the net income obtained by Enterprises $j$ in the manufacturing services industry which took the collaborative innovation strategy, assuming $x_{3}>x_{1}, x_{4}>x_{2}$.

$H_{4}$ : Assuming the Government provide the manufacturing services industry and manufacturing industry which conduct co-innovation with financial support, and the total government funds is $G$. The two parties of the game distribute the above funds reasonably according to the agreement. Wherein, $g_{1}$ is the government funds assigned to Enterprise $i$ in the manufacturing industry and $g_{2}$ is the government funds assigned to Enterprise $j$ in the manufacturing services industry. $\mathrm{H}_{5}$ : Assuming financial institutions raise funds for the manufacturing services industry and manufacturing industry which have collaborative innovation projects, the total input financial funds is $F$. The two parties of the game distribute the above funds reasonably according to the agreement. Wherein, $f_{1}$ is the financial funds assigned to Enterprise $i$ in the manufacturing industry and $f_{2}$ is the financial funds assigned to Enterprise $j$ in the manufacturing industry.

$H_{6}$ : In the collaborative innovation process, any party can obtain additional benefits because of the knowledge spillover of the other party after it withdraws from the system. wherein, $e_{1}$ is the additional benefits of Enterprise $i$ in the manufacturing industry because of the knowledge spillover of the other party after it withdraws from the co-innovation system and $e_{2}$ is the additional benefits of Enterprise $j$ in the manufacturing services industry because of the knowledge spillover of the other party after it withdraws from the co-innovation system. $H_{7}$ : It is fine $P$ paid by any party when it withdraws from the co-innovation system.

$H_{8}$ : It is the loss brought by any party withdrawing from the system. Wherein, $l_{1}$ is the losses suffered by Enterprise $i$ in the manufacturing due to the withdrawal of the member of the other party and $l_{2}$ is the losses suffered by Enterprise $j$ in the manufacturing services industry due to the withdrawal of the member of the other party.

$H_{9}$ : For both sides of the game, the strategy selection space is collaborative or non-collaborative. At the same time, it is assumed that the proportion of enterprises in the manufacturing industry choosing collaboration is $p$, the proportion of enterprises in the manufacturing industry choosing non-collaboration is $1-p$ in the initial stage of the evolutionary game, the proportion of enterprises for choosing collaboration is $q$, and the proportion of enterprises for choosing non-collaboration is 1-q. At the same time, it is assumed that all individuals in the same group have the same payoff.

\section{B. Payoff Matrix and Dynamic Equation of Replicator}

Under the above assumptions, the payment matrix of the coinnovation evolutionary game in manufacturing services industry and manufacturing is shown in Table 1.

Table 1 . The payment matrix of the co-innovation evolutionary

\begin{tabular}{|c|c|c|c|}
\hline \multicolumn{2}{|c|}{ game } \\
\cline { 3 - 4 } \multicolumn{2}{|c|}{} & \multicolumn{2}{c|}{ Manufacturing services industry } \\
\cline { 3 - 4 } Enterprise $i$ & Collaboration & Non-collaboration \\
\cline { 3 - 4 } & Collaboration & $x_{3}+g_{1}+f_{1}$ & $x_{3}+g_{1}+f_{1}-l_{1}$ \\
\cline { 2 - 4 } & $\begin{array}{l}\text { Non- } \\
\text { collaboration }\end{array}$ & $x_{4}+g_{2}+f_{2}$ & $x_{2}+e_{2}-P$ \\
\cline { 2 - 4 } & $x_{1}+e_{1}-P$ & $x_{1}$ \\
\hline
\end{tabular}

Based on the payoff matrices of the co-innovation evolutionary game model in manufacturing services industry and manufacturing industry, the replicator dynamic differential equation of co-innovation strategy in manufacturing industry can be obtained as

$$
d p / d t=p(1-p)\left[q\left(l_{1}-e_{1}+P\right)+\left(x_{3}+g_{1}+f_{1}-x_{1}-l_{1}\right)\right]
$$

In the same way, the replicator dynamic differential equation 
in manufacturing services industry can be obtained by choosing the collaborative innovation strategy as

$$
d q / d t=q(1-q)\left[p\left(l_{2}-e_{2}+p\right)+\left(x_{4}+g_{2}+f_{2}-l_{2}-x_{2}\right)\right]
$$

\section{Evolutionary Stabilization Strategy of Models}

The replicator dynamic differential equations of the evolutionary game in manufacturing services industry and manufacturing industry are Equations (1) and (2), assuming

$$
\begin{gathered}
L=l_{1}-e_{1}+P \\
M=x_{3}+g_{1}+f_{1}-x_{1}-l_{1} \\
N=l_{2}-e_{2}+P \\
Q=x_{4}+g_{2}+f_{2}-l_{2}-x_{2}
\end{gathered}
$$

The above-described replicator dynamic differential equations are reduced to the following Equations (7) and (8)

$$
\begin{aligned}
& d p / d t=p(1-p)(q L+M) \\
& d q / d t=q(1-q)(p N+Q)
\end{aligned}
$$

Assuming $d p / d t=d q / d t=0$ at the equilibrium point, then the equilibrium points $E_{1}$ to $E_{5}$ are obtained

$$
E_{1}(0,0), E_{2}(1,0), E_{3}(1,1), E_{4}(0,1), E_{5}(-Q / N,-M / L)
$$

The Jacobian matrix $J$ can be obtained by finding the partial derivative of the replicator dynamic differential equation, as shown in Formula (9).

$$
J=\left\lfloor\begin{array}{l}
\frac{d p / d t}{d p} \frac{d p / d t}{d q} \\
\frac{d q / d t}{d p} \frac{d q / d t}{d q}
\end{array}\right\rfloor
$$

Then find the partial differential of the replicator dynamic Equations (7) and (8) so as to obtain the Jacobian matrix $J$ of the model as Equation (10).

$$
\begin{aligned}
& J=\left\lfloor\begin{array}{ll}
(1-2 p)(q L+M) p(1-p) L \\
q(1-q) N & (1-2 q)(p N+Q)
\end{array}\right\rfloor \\
& =\left[\begin{array}{l}
(1-2 p)\left[q\left(l_{1}-e_{1}+p\right)+\left(x_{3}+g_{1}+f_{1}-x_{1}-l_{1}\right)\right] \\
q(1-q)\left(l_{2}-e_{2}+P\right)
\end{array}\right. \\
& p(1-p)\left(l_{1}-e_{1}+P\right) \\
& \left.(1-2 q)\left[p\left(l_{2}-e_{2}+p\right)+\left(x_{4}+g_{2}+f_{2}-l_{2}-x_{2}\right)\right]\right]
\end{aligned}
$$

\section{Solution to Co-InNovation Evolutionary GAME MODEL}

\section{A. The Stable Equilibrium Point of the Model}

The stability of solution of any linear system can be transformed into the stability of the zero solution of the corresponding linear system for the dynamical system theorem. As for $x=A, x \in R^{\wedge} n, A$ is the constant matrix of $n \times n$. The zero solution is a necessary condition for the locally asymptotic stable solution, which is all eigenvalues with negative real parts of $A$.

The stability of Equilibrium point $x_{j}$ can be determined according to the symbol of the real part of the eigenvalue $\lambda_{i}$ of $A=D f\left(x_{i}\right)$, and the equilibrium point $x_{i}$ is the asymptotic stable point. If Matrix $A$ has at least one positive eigenvalue, $x_{i}$ is the non-equilibrium point. The equilibrium points and eigenvalues are shown in Table 2.

Table 2. The evolutionary game model

\begin{tabular}{|c|c|}
\hline The equilibrium points & Eigenvalues \\
\hline$E_{1}(0,0)$ & $x_{3}+g_{1}+f_{1}-x_{1}-l_{1}$ \\
& $x_{4}+g_{2}+f_{2}-x_{2}-l_{2}$ \\
\hline$E_{2}(1,0)$ & $-x_{3}-g_{1}-f_{1}+x_{1}+l_{1}$ \\
& $-e_{2}+P+x_{4}+g_{2}+f_{2}-x_{2}$ \\
\hline$E_{3}(1,1)$ & $e_{1}-P-x_{3}-g_{1}-f_{1}+x_{1}$ \\
& $e_{2}-P-x_{4}-g_{2}-f_{2}+x_{2}$ \\
\hline$E_{4}(0,1)$ & $-e_{1}+P+x_{3}+g_{1}+f_{1}-x_{1}$ \\
& $-x_{4}-g_{2}-f_{2}+x_{2}+l_{2}$ \\
\hline$E_{5}(-\mathrm{Q} / \mathrm{N},-\mathrm{M} / \mathrm{L})$ & {$[\mathrm{NLQM}(\mathrm{NL}+\mathrm{NM}+\mathrm{QL}+\mathrm{QM})]^{-2} / \mathrm{NL}$} \\
& $-[\mathrm{NLQM}(\mathrm{NL}+\mathrm{NM}+\mathrm{QL}+\mathrm{QM})]^{-2} / \mathrm{N}$ \\
\hline
\end{tabular}

\section{B. The Stable Equilibrium Analysis of Evolutionary} Model

$$
\begin{aligned}
& \text { When } l_{1} \succ x_{3}+g_{1}+f_{1}-x_{1}, l_{2} \succ x_{4}+g_{2}+f_{2}-x_{2}, \\
& e_{1}-P \succ x_{3}+g_{1}+f_{1}-x_{1}, e_{2}-P \succ x_{4}+g_{2}+f_{2}-x_{2},
\end{aligned}
$$

the final proportion of manufacturing enterprises and producer services enterprises choosing collaborative strategy is $(0,0)$. When the losses suffered by any member's withdrawal of the other party from the collaborative innovation system are more than the co-innovation revenue obtained by choosing the collaborative innovation strategy, the normal return that can be obtained when the cooperative innovation strategy is not selected, the difference of the profit is less than the difference between the extra income obtained by the member and the paid fine is deducted from the member's knowledge spillover, the whole collaborative innovation system tends to not choose cooperative innovation strategy with the progress of time.

$$
\begin{aligned}
& \text { When } l_{1} \prec x_{3}+g_{1}+f_{1}-x_{1}, l_{2} \succ x_{4}+g_{2}+f_{2}-x_{2}, \\
& e_{1}-P \prec x_{3}+g_{1}+f_{1}-x_{1}, e_{2}-P \succ x_{4}+g_{2}+f_{2}-x_{2},
\end{aligned}
$$

the final proportion of manufacturing enterprises and manufacturing services enterprises choosing collaborative strategy is $(0,0)$. When the losses suffered by any manufacturing enterprises due to withdrawal of the other party from the collaborative innovation system are less than the coinnovation revenue obtained by choosing the collaborative innovation strategy, the normal return that can be obtained when the cooperative innovation strategy is not selected, and the difference of the profit is more than the difference between the extra income obtained by the member and the paid fine is deducted from the member's knowledge spillover. At the same time, the losses suffered by the manufacturing services due to 
the withdrawal of the other member is greater than that of the cooperative innovation which can be obtained when the cooperative innovation strategy is chosen, the normal return that can be obtained when the cooperative innovation strategy is not selected, the difference of the profit is less than the difference between the extra income obtained by the member and the paid fine is deducted from the member's knowledge spillover. The manufacturing enterprises tend to choose the strategy of collaborative innovation, and the manufacturing services enterprises tend not to choose the co-innovation strategy.

$$
\begin{aligned}
& \text { When } l_{1} \prec x_{3}+g_{1}+f_{1}-x_{1}, l_{2} \prec x_{4}+g_{2}+f_{2}-x_{2}, \\
& e_{1}-P \prec x_{3}+g_{1}+f_{1}-x_{1}, e_{2}-P \prec x_{4}+g_{2}+f_{2}-x_{2},
\end{aligned}
$$

the final proportion of manufacturing enterprises and manufacturing services enterprises choosing collaborative strategy is $(0,0)$. When the losses suffered by the withdrawal of a member of the collaborative innovation system is less than the co-innovation revenue obtained when the cooperative innovation strategy is chosen and the normal return obtained when the cooperative innovation strategy is not selected, and the difference of income is more than the difference between the extra income and the penalty paid by the withdrawing member due to the knowledge spillover of the member of other party. The whole collaborative innovation system tends to not choose cooperative innovation strategy with the progress of time.

$$
\begin{aligned}
& \text { When } l_{1} \succ x_{3}+g_{1}+f_{1}-x_{1}, l_{2} \prec x_{4}+g_{2}+f_{2}-x_{2}, \\
& e_{1}-P \succ x_{3}+g_{1}+f_{1}-x_{1}, e_{2}-P \succ x_{4}+g_{2}+f_{2}-x_{2},
\end{aligned}
$$

the final proportion of manufacturing industry and manufacturing services industry choosing collaborative strategy is $(0,1)$. When the losses suffered by manufacturing industry in the collaborative innovation system due to the other members' introduction are more than the income difference obtained by not choosing the collaborative innovation strategy and the difference income is less than the difference of the member withdrawing from the other party's knowledge spillover and the penalty paid. At the same time, the losses of the manufacturing service enterprises due to the withdrawal of the other party's members are less than the difference between the incomes by choosing cooperative innovation and the normal income by not choosing the cooperative innovation strategy .

$$
\begin{aligned}
& \text { When } l_{1} \succ x_{3}+g_{1}+f_{1}-x_{1}, l_{2} \succ x_{4}+g_{2}+f_{2}-x_{2}, \\
& e_{1}-P \prec x_{3}+g_{1}+f_{1}-x_{1}, e_{2}-P \prec x_{4}+g_{2}+f_{2}-x_{2},
\end{aligned}
$$

the final proportion of manufacturing enterprises and manufacturing services enterprises choosing collaborative strategy is $(0.0)$, it may also be $(1,1)$. And when $p \prec-Q / N$, $q \prec-M / L$, The proportion of the parties of producing and studying choosing co-innovation is lower than that of Nash equilibrium, and the game converges to the equilibrium point $E_{1}(0,0)$, indicating both parties of the game will not choose collaborative innovation. When $P \succ-Q / N, q \prec-M / L$, the proportion of the manufacturing choosing co-innovation is greater than that of Nash equilibrium, while the proportion of manufacturing services choosing co-innovation is less than that of Nash equilibrium, and the game may converge to the equilibrium point $E_{1}(0,0)$, it may also converge to the equilibrium point $E_{3}(1,1)$, indicating manufacturing services enterprises and manufacturing enterprises may choose coinnovation, they may also not choose co-innovation. When $p \succ-Q / N, q \succ-M / L$, the proportion of the manufacturing services and manufacturing industries choosing co-innovation is greater than that of Nash equilibrium, at this time, the game converges to the equilibrium point $E_{3}(1,1)$, indicating both parties of the game will choose collaborative innovation. When $p \prec-Q / N, q \succ-M / L$, the proportion of the manufacturing services industry choosing co-innovation is greater than that of Nash equilibrium, and the proportion of the manufacturing industry choosing co-innovation is lower than that of Nash equilibrium, at this time, the game converges to the equilibrium point $E_{1}(0,0)$, it may converge to the equilibrium point $E_{3}(1,1)$, both parties of the game may choose collaborative innovation, they may not choose collaborative innovation.

\section{RESEARCH DESIGN AND SAMPLE}

According to the theoretical deduction and analysis, the theoretical framework of innovation resource factors, industry embeddedness factors, institutional factors and symbiotic innovation ability on innovation performance is constructed, as shown in Figure 1. The mechanism of the recursive effect of innovation resource factors, industry embeddedness factors and system factors on innovation performance with symbiotic innovation capability as intermediary variable is investigated.

\section{A. Data Sample}

The related data collection of the conceptual model of the influencing factors of symbiotic innovation system needs to be conducted by questionnaire survey of large sample enterprises. Specifically, the survey object is manufacturing enterprises, and the conditions for sample selection are as follows. Firstly, the sample is the manufacturing enterprises related to producer services. Secondly, the region selected by the sample enterprises is the national region, so as to minimize the impact caused by the differences in economic development level of different regions. Thirdly, the growth period of sample enterprises must be three years or more to ensure that enterprises have a clear judgment on their own business situation, technological innovation level and environmental situation. Fourthly, the questionnaire respondents are middle and senior managers with more than two years' working experience to ensure that the respondents have enough ability and knowledge to ensure the quality of the answers. The issued questionnaires were 340 and 262 of them were confirmed through friend relationship, enterprise survey and face-to-face communication with MBA students. Among them, 227 were valid and the effective recovery rate was $86.6 \%$. The details are shown in Table 3. 


\section{B. Variable Measurement}

The scales used in this paper are Likert five point scale. The measurement of innovation resource factors mainly refers to the measurement scale designed by Literature[13], including four items such as "funds for technological transformation and $\mathrm{R} \& \mathrm{D}$ investment". The Cronbach $\alpha$ value of this scale is 0.888 . The measurement of industrial embeddedness factors mainly refers to the measurement scale designed by Literature[14], including 6 items such as "long-term cooperative relationship with partners and stable relationship". The Cronbach $\alpha$ value of the scale is 0.918 . The measurement of institutional factors mainly refers to the measurement scale designed by Literature[15], including four items such as "the improvement degree of platform construction to encourage innovation and cooperation", and the Cronbach $\alpha$ value of this scale is 0.874 . The measurement of symbiotic innovation ability mainly refers to the measurement scale designed by Literature[16] included 9 items such as "being able to effectively utilize knowledge belonging to different technologies or application fields".
The measurement of innovation performance factors mainly refers to the measurement scale designed by Literature[17], including 6 items such as "the sales proportion of innovative products increases", and the Cronbach $\alpha$ value of this scale is 0.890 . The details are shown in Table 4.

In this study, the author uses Mplus7.0 to analyze the factors of innovation resources, industry embeddedness, system, symbiotic innovation ability, environmental disturbance, innovation performance and other variables, and tests the validity of the above variables and measures the relevant parameters of the scale. The results of the comparison of the confirmatory factor analysis model can be obtained in Table 5.

The Cronbach $\alpha$ value of the scale was 0.885. The measurement of environmental disturbance factors mainly refers to the measurement scale designed by Literature[18]), including 6 items such as "customers are easy to accept new products", and the Cronbach $\alpha$ value of this scale is 0.898 .

Table 3. Distribution and recovery of questionnaires (Unit: Copies)

\begin{tabular}{cccccc}
\hline Distribution and recovery of questionnaires & $\begin{array}{c}\text { Distribution } \\
\text { quantity }\end{array}$ & $\begin{array}{c}\text { Quantity } \\
\text { recovered }\end{array}$ & $\begin{array}{c}\text { Recovery } \\
\text { rate }(\%)\end{array}$ & $\begin{array}{c}\text { Effective } \\
\text { quantity }\end{array}$ & $\begin{array}{c}\text { Effective } \\
(\%)\end{array}$ \\
\hline Entrust a friend, Distribution of colleague relations & 230 & 173 & 75.2 & 151 & 87.3 \\
$\quad$ Issued by the MBA center & 100 & 79 & 79 & 66 & 83.5 \\
The author paid a direct visit to the site & 10 & 10 & 100 & 10 & 100 \\
$\quad$ Total & 340 & 262 & 77.1 & 227 & 86.6 \\
\hline
\end{tabular}

Table 4. Reliability analysis of main construct scale

\begin{tabular}{ccc}
\hline Latent variable & Item & Cronbach's a \\
\hline Innovation resource factors & 4 & 0.888 \\
Industry embeddedness factors & 6 & 0.918 \\
Institutional factors & 4 & 0.874 \\
Symbiotic innovation capability & 9 & 0.885 \\
Environmental disturbance factors & 6 & 0.898 \\
Symbiotic innovation performance & 6 & 0.890 \\
\hline
\end{tabular}

Table 5. Comparison of confirmatory factor models

\begin{tabular}{ccccc}
\hline Model & $\chi^{2} / d f$ & CFI & TLI & RMSEA \\
\hline Six-factor & 1.328 & 0.959 & 0.955 & 0.038 \\
Five-factorl & 1.967 & 0.877 & 0.868 & 0.065 \\
Four-factor & 2.139 & 0.854 & 0.844 & 0.071 \\
Three-factor & 2.682 & 0.784 & 0.770 & 0.086 \\
Two-factor & 3.119 & 0.727 & 0.710 & 0.097 \\
Single-factor & 3.163 & 0.721 & 0.705 & 0.098 \\
\hline
\end{tabular}




\begin{tabular}{|c|c|c|c|c|c|c|}
\hline & $\begin{array}{l}\text { Innovation } \\
\text { resource } \\
\text { factors }\end{array}$ & $\begin{array}{l}\text { Industry } \\
\text { embeddedness } \\
\text { factors }\end{array}$ & $\begin{array}{c}\text { Institutional } \\
\text { factors }\end{array}$ & $\begin{array}{c}\text { Factors of } \\
\text { symbiotic } \\
\text { innovation } \\
\text { ability }\end{array}$ & $\begin{array}{l}\text { Environmental } \\
\text { disturbance } \\
\text { factors }\end{array}$ & $\begin{array}{l}\text { Innovation } \\
\text { performance }\end{array}$ \\
\hline $\begin{array}{c}\text { New resource } \\
\text { factors } \\
\text { Industry }\end{array}$ & $(0.6632)$ & & & & & \\
\hline $\begin{array}{l}\text { embeddedness } \\
\text { factors }\end{array}$ & $0.456 * *$ & $(0.6512)$ & & & & \\
\hline Institutional factors & $0.506^{* *}$ & $0.616 * *$ & $(0.6359)$ & & & \\
\hline $\begin{array}{c}\text { Factors of } \\
\text { symbiotic } \\
\text { innovation ability }\end{array}$ & $0.556 * *$ & $0.470 * *$ & $0.458 * *$ & $(0.5626)$ & & \\
\hline $\begin{array}{c}\text { Environmental } \\
\text { disturbance factors }\end{array}$ & $0.481 * *$ & $0.526 * *$ & $0.531 * *$ & $0.519 * *$ & $(0.5557)$ & \\
\hline $\begin{array}{l}\text { Innovation } \\
\text { performance }\end{array}$ & $0.694 * *$ & $0.682 * *$ & $0.706 * *$ & $0.712 * *$ & $0.686^{* *}$ & $(0.7767)$ \\
\hline Standard deviation & 0.717 & 0.788 & 0.812 & 0.595 & 0.714 & 0.738 \\
\hline Mean value & 3.190 & 3.276 & 3.255 & 3.341 & 3.258 & 3.257 \\
\hline
\end{tabular}

Note: $* \mathrm{p}<0.05, * * \mathrm{p}<0.01, \mathrm{P} * * *<0.001$

\section{EMPIRICAL ANALYSIS}

\section{A. Correlation Analysis}

In this paper, SPSS24.0 was used to analyze the correlation of variables (see Table 6). The data showed that the factors of innovation resources and innovation performance $(r=0.6632$, $\mathrm{P}<0.01)$, the factors of industrial Embeddedness and innovation performance $(\mathrm{r}=0.6512, \mathrm{P}<0.01)$, the factors of institution and symbiotic innovation ability $(\mathrm{r}=0.6359, \mathrm{P}<$ 0.01 ), the symbiotic innovation ability and innovation performance $(\mathrm{r}=0.5026, \mathrm{P}<0.01)$, The results of correlation analysis showed that there was significant $(\mathrm{r}=0.5557, \mathrm{P}<0.01)$, environmental disturbance factors and innovation performance $(\mathrm{r}=0.5557, \mathrm{P}<0.01)$. The results of the data preliminarily verify the hypothesis relationship between variables, so hypothesis testing can be continued. The data in the diagonal brackets of the table are the square root of ave of each latent variable, and they are all greater than 0.5 , indicating that the discriminant validity is good.

Note: five factors a innovation resource factor + industry embeddedness factor, B system factor, $\mathrm{C}$ symbiotic innovation ability factor, D environment disturbance factor, e innovation performance factor; four factor a innovation resource factor + industry embeddedness factor + system factor, B symbiotic innovation ability factor, $\mathrm{C}$ environment disturbance factor and $\mathrm{D}$ innovation performance factor; three factor a innovation resource factor + industry embeddedness factor + system factor + symbiotic innovation capability factor Factors a, B environmental disturbance factor, $\mathrm{C}$ innovation performance; double factor a innovation resource factor + industry embeddedness factor + system factor + symbiotic innovation ability factor + environment disturbance factor, B innovation performance.

\section{B. Hypothesis Test}

This study constructs structural equation model of influencing factors (resource factors, industrial embeddedness factors, institutional factors), intermediary variables (symbiotic innovation ability factors), regulatory variables (environmental disturbance factors), and dependent variables (innovation performance) through Mplus7.0 software. The results of fitting degree are shown in Table 7. The results show that $\chi^{2} / d f=1.328$, CFI $=0.959$, TLI $=0.955$, RMSEA $=$ 0.038 , and the fitting index meets the discriminant standard. The overall model has a good fitting degree, which can be used to judge the theoretical hypothesis proposed in this paper. According to the path coefficients among potential variables of the model (Table 8), the standardized path coefficients are all greater than 0 , that is, hypothesis are supported. Bootstrap is used to test the mediating effect. The $95 \%$ confidence interval is calculated by repeated sampling for 1000 times. The results are shown in Table 9.

The confidence interval estimated by the path coefficient of indirect effect does not include 0 , indicating that the mediating effect of symbiotic innovation capability on this path is significant, Combined with the analysis of the main effect in the previous paper, symbiotic innovation capability plays a part of intermediary role between the factors of innovation resources, industry embeddedness, institutional factors and innovation performance. 
Table 7. The fitting degree of overall structure model scale

\begin{tabular}{ccccc}
\hline Fitting Index & CMIN/DF & RMSEA & CFI & TLI \\
\hline Standard & $<2.00$ & $<0.08$ & $>0.9$ & $>0.9$ \\
Numerical Value & 1.328 & 0.038 & 0.959 & 0.955 \\
\hline
\end{tabular}

Table 8 . The path coefficient and hypothesis verification of theoretical

\begin{tabular}{|c|c|c|c|c|c|}
\hline Path & S.E. & C.R. & $\mathrm{P}$ & $\begin{array}{c}\text { Standardized } \\
\text { path coefficient }\end{array}$ & Test results \\
\hline $\begin{array}{c}\text { Innovation resource factor-Innovation } \\
\text { performance }\end{array}$ & 0.064 & 4.771 & 0.000 & 0.306 & adopt \\
\hline $\begin{array}{l}\text { Industry embeddedness factor-Innovation } \\
\text { performance }\end{array}$ & 0.081 & 1.21 & 0.000 & 0.099 & adopt \\
\hline Institutional factors-Innovation performance & 0.082 & 2.790 & 0.005 & 0.23 & adopt \\
\hline $\begin{array}{c}\text { Innovation resource factor-Symbiotic innovation } \\
\text { capability factor }\end{array}$ & 0.089 & 4.147 & 0.000 & 0.369 & adopt \\
\hline $\begin{array}{l}\text { Industry embeddedness factor-Symbiotic } \\
\text { innovation ability factor }\end{array}$ & 0.135 & 0.763 & 0.045 & 0.103 & adopt \\
\hline $\begin{array}{l}\text { Institutional factors-Symbiotic innovation } \\
\text { capability }\end{array}$ & 0.145 & 2.403 & 0.016 & 0.347 & adopt \\
\hline Symbiotic innovation capability factor & 0.064 & 4.433 & 0.000 & 0.286 & adopt \\
\hline
\end{tabular}

Table 9. Bootstrapping analysis of mediating effect significance test model

\begin{tabular}{|c|c|c|c|c|}
\hline \multirow[t]{2}{*}{ route } & \multirow{2}{*}{$\begin{array}{c}\text { effect } \\
\text { (Symbiotic innovation } \\
\text { capability) }\end{array}$} & \multicolumn{2}{|c|}{$\begin{array}{l}\text { Confidence Interval ( } \\
95 \%)\end{array}$} & \multirow[t]{2}{*}{ Significance } \\
\hline & & Lower & Upper & \\
\hline $\begin{array}{l}\text { Innovation resource factor-Symbiotic innovation } \\
\text { capability-Innovation performance }\end{array}$ & Indirect effect & 0.051 & 0.160 & $* * *$ \\
\hline $\begin{array}{l}\text { Industry embeddedness factor-Symbiotic } \\
\text { innovation capability-Innovation performance }\end{array}$ & Indirect effect & 0.037 & 0.096 & $* * *$ \\
\hline $\begin{array}{l}\text { Institutional factors-Symbiotic innovation } \\
\text { capability-Innovation performance }\end{array}$ & Indirect effect & 0.019 & 0.179 & $* * *$ \\
\hline
\end{tabular}




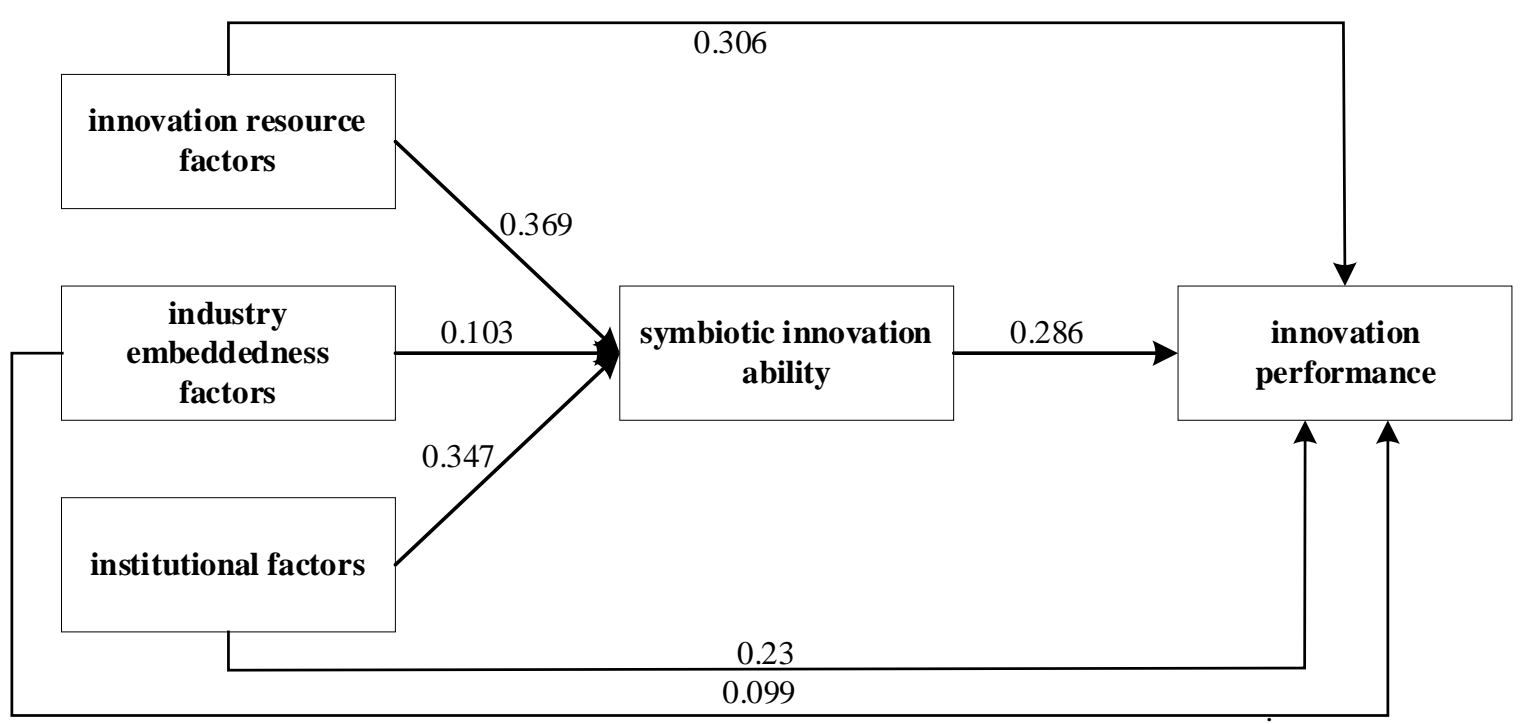

Fig. 1. The conceptual model of influencing factors of symbiotic innovation

\section{CONCLUSION}

In summary, there are five equilibrium solutions for the evolutionary game model of collaborative innovation in manufacturing services industry and manufacturing industry, they are respectively $E_{1}(0,0), E_{2}(1,0), E_{3}(1,1), E_{4}(0,1), E_{5}(-$ $\mathrm{Q} / \mathrm{N},-\mathrm{M} / \mathrm{L})$. Wherein, $E_{5}(-Q / N,-M / L)$ is the saddle point of the system, and the other points in different constraints are stable. The losses suffered by one party due to the withdrawal of the other party's members who choose the collaborative innovation strategy, the normal revenue obtained when the member choose the non-cooperative innovation strategy, the difference between the additional income obtained by the knowledge spillover and the penalty paid are the basis for strategy making for the manufacturing services industry and manufacturing industry. Due to the abstraction of model research, many influencing factors are simplified in the modeling process, which may lead to some differences between the research conclusions and the actual collaborative innovation. This problem will be improved in the future research.

Taking manufacturing enterprises related to producer services as research samples, this paper examines the mechanism on innovation performance through symbiotic innovation system. However, the interaction between $\mathrm{HJ}$ and $\mathrm{NL}$ failed to pass the test. It shows that HJ does not play a role in regulating symbiotic innovation capability and symbiotic innovation performance. According to the above empirical analysis results, the final influencing factors of symbiotic innovation of manufacturing industry and producer service industry are obtained, as shown in Figure 1.

The symbiotic innovation is the result of many factors. First of all, innovation resources have a positive impact. Innovation resources are the material basis of symbiotic innovation, and the innovation performance is determined by the innovation resources of innovation subjects. Secondly, the industrial embeddedness factors have a positive impact on the symbiotic innovation ability and innovation performance. Producer 
services and manufacturing industries have strong industrial correlation. Industrial embeddedness is conducive to the manufacturing industry to retain the core link, and also promote the knowledge spillover of the symbiotic innovation system to form the innovation of the value chain. Thirdly, institutional factors have a positive impact on symbiotic innovation capability and innovation performance. Institution can restrict the interaction of actors with certain rules, reduce uncertainty, inhibit opportunistic behavior of actors, and improve the standardization of actors. It is the policy guarantee for the operation of symbiotic innovation system and an important external incentive for the evolution of industrial symbiotic innovation system.

Symbiotic innovation ability plays an intermediary role in the factors of innovation resources, industry Embeddedness and the relationship between institutional factors and innovation performance. Symbiotic innovation ability can promote innovation performance through the interaction of resource integration ability, collaborative cooperation ability and innovation transformation ability. The four abilities interact and complement each other, making symbiotic innovation ability become a transformation mechanism, and different combinations of innovation resources, industry Embeddedness and system degree can be transformed into symbiotic innovation capability. Therefore, symbiotic innovation ability provides a new perspective for the research of symbiotic innovation system, and is an important factor to realize symbiotic innovation between manufacturing and productive service industries.

As a moderator, Environmental disturbance has not passed the test. As far as this study is concerned, there may be the following reasons. For example, when the technology disturbance is strong, the decision-making department of the innovation subject may perceive the information of various technological updates in different technical fields at the same time, leading to the interference of complex technical information on the innovation subject, reducing the cognitive level of the innovation subject's decision-making strategy, and improving the innovation performance, which makes the promotion effect diluted. When the market disturbance is enhanced, it will give birth to some new market opportunities, which means the breakthrough point or breakthrough point of innovation behavior for the innovation subject.

There are some deficiencies in the research. In this study, environmental disturbance factors as the moderating role has not passed the test. This conclusion also confirms the debate about whether environmental disturbance factors are regulatory variables or driving factors. It is necessary to further analyze this in future research. In addition, there is no in-depth case study on typical enterprises based on process. Therefore, it is necessary to test the composition of these important concepts and their relationship with each other through case study in the future research.

\section{REFERENCES}

[1] Drechsler W, Natter M., Understanding a firm's openness decisions in innovation. Journal of Business Research, 2019, 65(3), pp.438-445.
[2] Gulati R, Sytch M., Dependence asymmetry and joint dependence in interorganizational relationships: effects of embeddedness on a manufacturer's performance in procurement relationships. Administrative Science Quarterly, 2018, 52, pp.32-69.

[3] Maarten Cuigpersa et.al., Costs ans Benefits of interdepartmental innovation collaboration, Research Policy, 2020, 40(4), pp.565-575.

[4] Subramaniam M, Youndt MA. The Influence of Intellectual Capital on the Types of Innovative Capabilities. Academy of Management Journal, 2019, 48(3), pp.450-463.

[5] Tsou H-T, Hsu SH-Y. Performance Effects of Technology-Organization-Environment Openness, Service Co-Production and Digital-Resource Readiness: The Case of the IT Industry. International Journal of Information Management, 2015, 35(1), pp.1-14.

[6] Olausson D, Berggren C. Managing Asymmetries in Informantion Flows and Interaction between R\&D, Manufacturing and Service in Complex Product Development. R\&D Management, 2021, 42(4), pp.342357.

[7] Doving E Gooderham P N. Dynamic Capabilities as Antecedents of the Scope of Related Diversification:the Case of Small Firm Accountancy Practices. Strategic Management Journal, 2018, 29(6), pp.841-857.

[8] Gilbert C. Unbundling the Structure of Inertia: Resource Versus Routine Rigidity. Academy of Management Journal, 2019,48(5), pp.741-763.

[9] Uyarra E, Edler J, Garcia-Estevez J, Georghiou L, Yeow J. Barriers to Innovation through Public Procurement: A Supplier Perspective. Technovation 2020, 34(10), pp.631638.

[10] Yam R C M, Lo W, et al. Analysis of Source of Innovation,Echnological Innovation Capabilities and Performance: an Empirical Study of Hong Kong Manufacturing Industries. Rearch Policy, 2021, (40), pp.391-402.

[11] Baldwin C, Hipped V E. Modeling a Paradigm Shift:from Producer Innovation to User and Open Collaborative Innovation. Organization Science, 2021, 22(6), pp.13991417.

[12] Lichtenthaler,M Muethel. The Impact of Family Involvement on Dynamic Innovation Capobilities: Evidence from Manufacturing Firms. Entrepreneurship Theory and Practice, 2019, 36(6), pp.1235-1253..

[13] Teece D J \& Pisano G, Shuen A. Dynamic Capabilities and Strategic Management. Strategic Management Journal, 2017, 18(7), pp.509-533.

[14] Rongshan Li, Yu Lu, Research on the Over-outsourcing in Aviation Manufacturing Industry - Case Analysis based on the Boeing 7871, WSEAS Transactions on Business and Economics, Volume 17, 2020, Art. \#49, pp. 505-513.

[15] Teuta Xhindi, Kevin Shestani, Financial Distress and Bankruptcy Prediction: An Empirical Analysis of the Manufacturing Industry in Albania, WSEAS Transactions on Business and Economics, Volume 17, 2020, Art. \#5, pp. 33-40. 
[16] Sukanya Intarapak, Thidaporn Supapakorn, Application of Logistic Regression Analysis to Household Debt of Bangkok and Metropolitan Area of Thailand, WSEAS Transactions on Business and Economics, Volume 17, 2020, Art. \#65, pp. 676-681.

[17] Saleh Ali Alomari, Safwan Al Salaimeh, Emran Al Jarrah, Mowafaq Salem Alzboon, Enhanced Logistics Information Service Systems Performance: Using Theoretical Model and Cybernetics?Principles, WSEAS Transactions on Business and Economics, Volume 17, 2020, Art. \#29, pp. 278-287.

[18] Jiskani I M , Han S , Rehman A U, et al. An Integrated Entropy Weight and Grey Clustering Method-Based Evaluation to Improve Safety in Mines. Mining Metallurgy \& Exploration, 2021(10), pp.237-249.
Creative Commons Attribution License 4.0 (Attribution 4.0 International, CC BY 4.0)

This article is published under the terms of the Creative Commons Attribution License 4.0

https://creativecommons.org/licenses/by/4.0/deed.en_US 